\title{
ACOPLAMENTO DE CELA DE DIFUSÃO GASOSA A SISTEMA DE ANÁLISE POR INJEÇÃO SEQÜENCIAL VISANDO A DETERMINAÇÃO ESPECTROFOTOMÉTRICA DE SULFETO
}

\author{
Marcelo Solitrenick Pinto Silva e Jorge Cesar Masini* \\ Instituto de Química, Universidade de São Paulo, C P 26077, 05513-970 São Paulo - SP
}

Recebido em 23/5/03; aceito em 27/11/03; publicado na web em 27/05/04

\begin{abstract}
COUPLING A GAS DIFFUSION CELL TO A SEQUENTIAL INJECTION SYSTEM FOR SPECTROPHOTOMETRIC DETERMINATION OF SULFIDE. A new configuration for coupling a gas diffusion cell to a sequential injection system is presented. The matrix exchange is made without the need for additional rotary injection valves or peristaltic pumps, keeping the original mechanical components of the sequential injection apparatus: one syringe pump (or peristaltic pump) and one selection valve. The system was tested constructing analytical curves for sulfide exploring the formation of the methylene blue dye. The proposed method has a detection limit of $60 \mu \mathrm{g} \mathrm{L}^{-1} \mathrm{~S}^{2-}$, with a linear dynamic range between 0.10 and $4.0 \mathrm{mg} \mathrm{L}^{-1} \mathrm{~S}^{2-}$ concentrations, with a sampling frequency of $20 \mathrm{~h}^{-1}$.
\end{abstract}

Keywords: sequential injection analysis; gas diffusion; sulfide.

\section{INTRODUÇÃO}

Celas de difusão gasosa são bastante utilizadas em análises em fluxo para realizar a chamada mudança de matriz. O analito é convertido em uma espécie gasosa que se difunde através de uma membrana, sendo recolhido em uma solução receptora que é posteriormente analisada ${ }^{1}$.

Alguns trabalhos da literatura descrevem métodos analíticos baseados em Análise por Injeção Seqüencial (SIA) utilizando-se celas de difusão gasosa. Por exemplo, a determinação de nitrogênio total e frações em silagem de alimentação animal foi descrita por Silva et $a l^{2}$. Neste sistema duas bombas peristálticas são utilizadas, sendo uma para formar a solução doadora que gera $\mathrm{NH}_{3}$ e outra que atua bombeando a solução receptora contendo os íons $\mathrm{NH}_{4}^{+}$em direção ao detector. Um sistema similar foi utilizado para determinação de uréia em amostras de leite ${ }^{3}$. Segundo et al. ${ }^{4}$ desenvolveram um método de injeção seqüencial para determinação de dióxido de enxofre em vinho também utilizando duas ou três bombas peristálticas, dependendo do objetivo do experimento. Echols et al. ${ }^{5}$ também utilizaram uma configuração com duas bombas peristálticas para a determinação de azoteto em explosivos. Sistemas de bombeamento e válvulas adicionais também foram utilizados para determinação de amônia em amostras gasosas ${ }^{6,7}$. A determinação de nitrogênio amoniacal e amônia livre em meio de fermentação foi proposta por Lukkari et al. ${ }^{8}$, sendo que estes autores utilizaram duas bombas de pistão e duas válvulas seletoras. Em outros trabalhos ${ }^{9,10}$, a determinação de íons amônio foi realizada acoplando-se a cela de difusão gasosa a uma válvula rotatória de seis portas e duas vias. Em todos estes trabalhos, a implementação da cela de difusão envolveu o uso de bombas e/ou válvulas rotatórias adicionais à configuração básica do sistema SIA, constituído por uma válvula seletora conectada à bomba de pistão e ao detector.

A técnica de análise por injeção seqüencial foi proposta inicialmente para o monitoramento de processos industriais, em situações nas quais o equipamento deve funcionar por prolongados períodos

*e-mail: jcmasini@iq.usp.br de tempo, sem necessidade de manutenção e de recalibrações freqüentes ${ }^{11}$. Neste sentido, quanto mais simples for o arranjo mecânico, maior a robustez do sistema, atendendo aos requisitos de estabilidade necessários nos ambientes de monitoramento de processo.

No presente trabalho propõe-se a associação da Análise por Injeção Seqüencial à Difusão Gasosa (GD-SIA) para a determinação de sulfeto, mantendo-se a configuração básica do sistema SIA. Neste caso, a cela de difusão é conectada a duas portas da válvula seletora, em uma configuração ainda não proposta na literatura.

\section{PARTE EXPERIMENTAL}

\section{Reagentes}

Todos os reagentes utilizados neste trabalho foram de grau analítico fornecidos pela Aldrich, Merck, Sigma ou Carlo Erba.

As soluções estoque de sulfeto foram preparadas diariamente na concentração de $100 \mathrm{mg} \mathrm{L}^{-1} \mathrm{em} \mathrm{S}^{2-}$ por dissolução da quantidade apropriada do sal $\mathrm{Na}_{2} \mathrm{~S} .9 \mathrm{H}_{2} \mathrm{O}$ em meio de $\mathrm{NaOH} 25 \times 10^{-3} \mathrm{~mol} \mathrm{~L}^{-1}$ usando água desionizada previamente fervida para eliminação de $\mathrm{O}_{2}$ dissolvido. Esta solução foi padronizada com uma solução de iodo padrão terciário de concentração $(12,62 \pm 0,06) \times 10^{-3} \mathrm{~mol} \mathrm{~L}^{-1}$ e de tiossulfato padrão secundário de concentração $(24,96 \pm 0,06) \times 10^{-3} \mathrm{~mol} \mathrm{~L}^{-1}$, que fora previamente padronizada com dicromato de potássio e iodeto. A partir desta solução foram preparadas as soluções de trabalho em uma faixa de concentração de sulfeto entre 0,10 e $5,0 \mathrm{mg} \mathrm{L}^{-1}$. Todas as soluções de trabalho foram preparadas em meio de $\mathrm{NaOH}$ $25 \times 10^{-3} \mathrm{~mol} \mathrm{~L}^{-1}$.

$\mathrm{O} \mathrm{H}_{2} \mathrm{~S}$ que sofre difusão na cela foi gerado a partir da reação das soluções de trabalho com uma solução de $\mathrm{H}_{2} \mathrm{SO}_{4} 1,0 \mathrm{~mol} \mathrm{~L}^{-1}$ e a solução receptora também foi uma solução de $\mathrm{NaOH} 25 \times 10^{-3} \mathrm{~mol} \mathrm{~L}^{-1}$.

A determinação de sulfeto foi baseada na formação de azul de metileno, na qual são utilizados dois reagentes:

R1: solução de dicloridrato de N,N-dimetil p-fenileno diamina

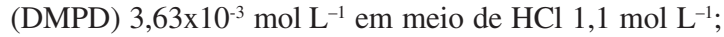

R2: solução de cloreto de ferro III $19 \times 10^{-3} \mathrm{~mol} \mathrm{~L}^{-1}$ em meio de $\mathrm{HCl}$ $1,1 \mathrm{~mol} \mathrm{~L}^{-1}$.

O transportador utilizado durante os experimentos foi uma solução de $\mathrm{HCl}$ de concentração $1,1 \mathrm{~mol} \mathrm{~L}^{-1}$. 


\section{Equipamentos}

Em todos os experimentos utilizou-se o equipamento FiaLab 3500 da FIALab Instruments (Bellevue, WA, USA) montado conforme descrito na Figura 1. As soluções foram impulsionadas através do sistema com uma bomba de pistão (SP). O direcionamento das soluções através do sistema foi obtido utilizando-se uma válvula seletora (RV) de oito portas da Valco Instrument Company (Houston, TX, USA).

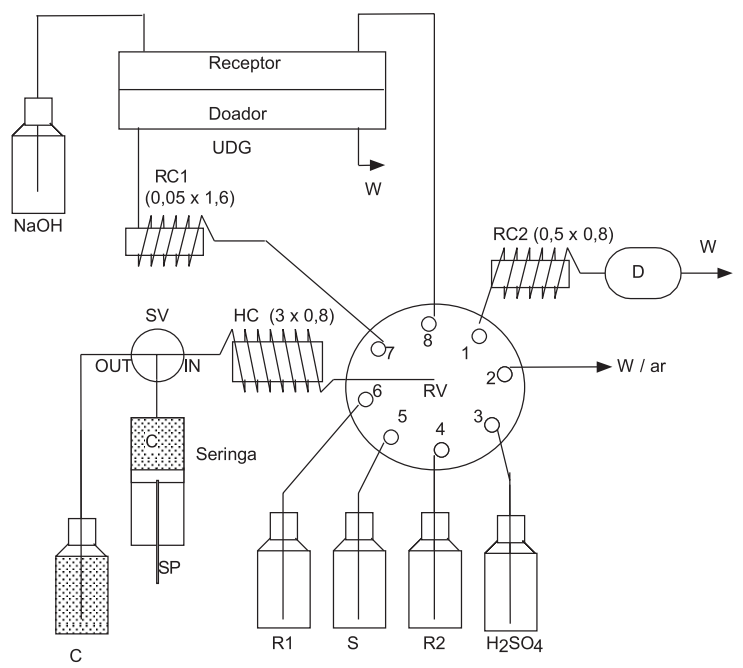

Figura 1. Representação esquemática da montagem da injeção seqüencial acoplada à cela de difusão gasosa: $U D G=$ unidade de difusão gasosa;

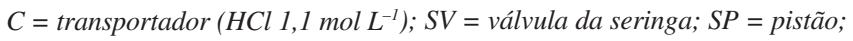
$H C=$ bobina coletora $; V=$ válvula seletora rotatória com 8 portas; $R 1=$ reagente $1\left(D M P D 3,63 \times 10^{-3} \mathrm{~mol} \mathrm{~L}^{-1}\right) ; R 2=$ reagente $2\left(\mathrm{FeCl}_{3} 19 \times 10^{-3}\right.$ mol $\left.L^{-1}\right) ; S=$ solução de trabalho de sulfeto; $\mathrm{NaOH}=$ reservatório com solução de $\mathrm{NaOH} 25 \times 10^{-3} \mathrm{~mol} \mathrm{~L}^{-1} ; \mathrm{H}_{2} \mathrm{SO}_{4}=$ reservatório com solução de $\mathrm{H}_{2} \mathrm{SO}_{4} 1,0 \mathrm{~mol} \mathrm{~L} \mathrm{~L}^{-1}$; $\mathrm{RC1}$ e $\mathrm{RC2}$ = bobinas de reação feitas de PTFE (os números entre parênteses em $\mathrm{HC}, \mathrm{RC1}$ e RC2 referem-se ao comprimento em $m x$ diâmetro interno em $\mathrm{mm}$ ); $W=$ descarte; $D=$ detector espectrofotométrico $(\lambda=745 \mathrm{~nm})$

A bobina coletora (HC) foi construída com um tubo de Teflon de $3 \mathrm{~m}$ de comprimento e diâmetro interno de $0,8 \mathrm{~mm}$ e as bobinas de reação, RC1 e RC2, também com tubos de Teflon. As dimensões de RC1 são 0,05 m de comprimento e diâmetro interno (d.i.) 1,6 $\mathrm{mm}$. RC2 possui $0,5 \mathrm{~m}$ de comprimento e d.i. $0,8 \mathrm{~mm}$. Todas as conexões entre os reservatórios de reagentes e padrões com as portas da válvula de seleção foram feitas ou com tubos de Teflon de diâmetro interno 0,5 mm ou com conexões, também em Teflon, da Upchurch (Oak Harbor, WA, USA). A detecção foi feita com um espectrofotômetro da Micronal modelo B382 (São Paulo, SP, Brasil) com uma cela de fluxo com formato em U de $10 \mathrm{~mm}$ de caminho ótico e $80 \mu \mathrm{L}$ de volume interno (Hellma GmbH\&Co., Mulheim, Baden, Alemanha). O controle da válvula de pistão e da válvula seletora multiportas foi feito com o software FiaLab 3500, e a aquisição dos dados com a placa PC-LPM-16 da National Instruments (Austin, TX, USA).

A cela de difusão foi construída utilizando-se materiais de baixo custo como tubos de Tygon, acrílico, placa de cloreto de polivinila PVC (régua escolar do tipo "Molegata" fabricada pela Trident), parafusos, arruelas e porcas metálicas (Figura 2). A membrana de difusão consistiu em uma tira de veda rosca comercial feita de Teflon. Esta tira, ao ser colocada na cela, foi esticada no sentido de alargá-la para ficar o mais fina possível, porém sem se romper, pretendendose com isso facilitar a difusão. O volume de solução receptora e solução doadora no interior da cela é da ordem de $220 \mu \mathrm{L}$.

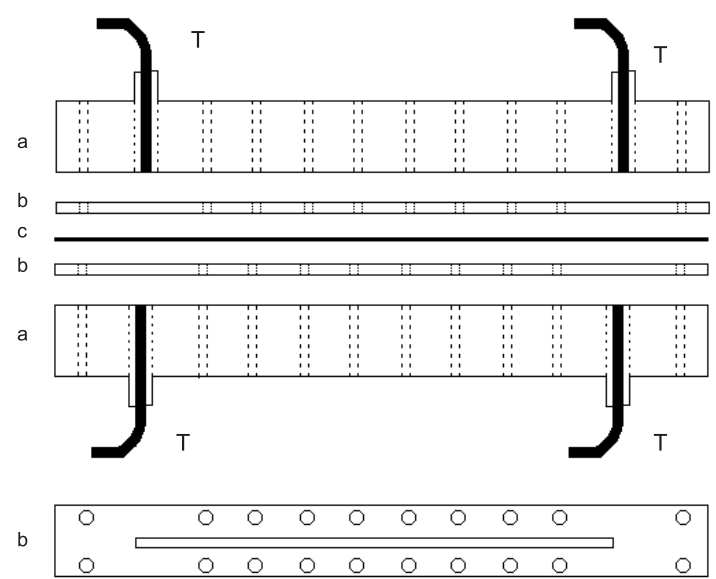

Figura 2. Esquema da cela de difusão gasosa com membrana de PTFE. apeça de acrílico (altura 1,8 cm; largura 2,8 cm; comprimento 28,6 cm); bespaçador de PVC com altura de $0,8 \mathrm{~mm}$, largura $2,8 \mathrm{~cm}$ e comprimento $28,6 \mathrm{~cm}$. O vão central possui $26 \mathrm{~cm}$ de comprimento e 1,0 $\mathrm{mm}$ de largura; c-membrana de Teflon; $T$ - tubo de Tygon (1,42 mm de diâmetro interno). OBS: Em cada uma das peças de acrílico não é feito nenhum canal, apenas vinte furos de diâmetro $5 \mathrm{~mm}$ para permitir a passagem dos parafusos de fixação e dois furos de 2,2 mm para passagem dos tubos de Tygon

\section{Procedimento de análise por injeção seqüencial acoplada à difusão gasosa}

As descrições a seguir estão baseadas na Figura 1.

Antes de executar-se o programa, o espectrofotômetro foi ajustado em $745 \mathrm{~nm}$, as bobinas $\mathrm{HC}, \mathrm{RC} 1 \mathrm{e}$ RC2 foram preenchidas com a solução transportadora $\left(\mathrm{HCl} 1,1 \mathrm{~mol} \mathrm{~L}^{-1}\right)$ e os tubos conectando cada reservatório a uma porta da válvula de seleção foram preenchidos com as respectivas soluções:

- porta 3: solução de $\mathrm{H}_{2} \mathrm{SO}_{4} 1,0 \mathrm{~mol} \mathrm{~L}^{-1}$ (reservatório $\mathrm{H}_{2} \mathrm{SO}_{4}$ );

- porta 4: solução de $\mathrm{FeCl}_{3} 19 \times 10^{-3} \mathrm{~mol} \mathrm{~L}^{-1}$ (reservatório R2);

- porta 5: solução de trabalho de $\mathrm{S}^{2-}$ (reservatório $\mathrm{S}$ );

- porta 6: solução de DMPD 3,63 x $10^{-3} \mathrm{~mol} \mathrm{~L}^{-1}$ (reservatório R1); - porta 8 (e a parte denominada "receptor" da cela de difusão): solução de $\mathrm{NaOH} 25 \times 10^{-3} \mathrm{~mol} \mathrm{~L}^{-1}$ (reservatório $\mathrm{NaOH}$ ).

Primeiramente a válvula da seringa $\mathrm{SV}$ conectou o pistão SP com o reservatório de solução transportadora, C, (posição "OUT") e, com uma vazão de $500 \mu \mathrm{L} \mathrm{s}^{-1}$, aspiraram-se para dentro da seringa, $2500 \mu \mathrm{L}$ de solução transportadora. A válvula da seringa conectou, então, a seringa com a válvula seletora RV (posição "IN") e, após $\mathrm{RV}$ posicionar-se na porta 7, SP dispensou $1000 \mu \mathrm{L}$ de transportador na cela de difusão através de RC1 com uma vazão de $100 \mu \mathrm{L} \mathrm{s}^{-1}$. Na seqüência, a válvula seletora mudou para a porta 8 e, com uma vazão de $50 \mu \mathrm{L} \mathrm{s}^{-1}$, foram aspirados $900 \mu \mathrm{L}$ de solução de $\mathrm{NaOH}$ pela cela de difusão. Por fim, a seringa foi esvaziada pela porta 2 a uma vazão de $500 \mu \mathrm{L} \mathrm{s}^{-1}$. Nos procedimentos de injeção seqüencial a bomba de pistão é parada cada vez que a válvula seletora, $R V$, ou a válvula da seringa, SV, está girando, evitando-se diferenças de pressão e conseqüente formação não controlada de bolhas.

A válvula da seringa SV mudou para a posição "OUT" e, sem alterar a vazão, foram aspirados para dentro da seringa $4850 \mu \mathrm{L}$ de solução transportadora. Então, SV retornou para a posição "IN" (com RV na porta 2) e, com uma vazão de $50 \mu \mathrm{L} \mathrm{s}^{-1}$, aspiraram-se para dentro de $\mathrm{HC}, 150 \mu \mathrm{L}$ constituídos de solução transportadora e ar. Em seguida, RV conectou-se à porta 1 e $200 \mu \mathrm{L}$ de solução transportadora foram dispensados a uma vazão de $50 \mu \mathrm{L} \mathrm{s}{ }^{-1}$. Aumentou-se então a vazão para $200 \mu \mathrm{L} \mathrm{s}$ s $^{-1}$ e mais $1200 \mu \mathrm{L}$ de solução transportadora foram dispensados pela porta $1 \mathrm{de} \mathrm{RV}$. Com isso, a porta 2 ficou 
em contato com o ar atmosférico e a cela de fluxo preenchida com solução transportadora.

$\mathrm{O} \mathrm{H}_{2} \mathrm{~S}$ a ser difundido foi gerado pela reação da solução de trabalho de sulfeto com uma solução de $\mathrm{H}_{2} \mathrm{SO}_{4} 1,0 \mathrm{~mol} \mathrm{~L}^{-1}$. Para minimizar a dispersão desta mistura com a solução transportadora, aspirou-se uma bolha de ar de $50 \mu \mathrm{L}$ para dentro da bobina coletora (HC) antes de iniciar-se a aspiração da solução doadora (mistura da solução de trabalho com a solução de $\left.\mathrm{H}_{2} \mathrm{SO}_{4}\right)^{12,13}$. Esta bolha foi aspirada pela porta 2 a uma vazão de $100 \mu \mathrm{L} \mathrm{s}^{-1}$ e, na seqüência, foram aspirados, com a mesma vazão, $200 \mu \mathrm{L}$ de solução de $\mathrm{H}_{2} \mathrm{SO}_{4}$ pela porta 3 e $950 \mu \mathrm{L}$ de solução de sulfeto (S) pela porta 5. Para melhor homogeneização (e consequiente reação entre $\mathrm{o}_{2} \mathrm{SO}_{4}$ e o sulfeto para formar $\mathrm{H}_{2} \mathrm{~S}$ ) estes volumes foram fracionados de uma forma similar à amostragem binária proposta por Reis et al. ${ }^{14}$. Na Figura 3 está representado, de forma esquemática, este fracionamento. Não foi aspirada uma segunda bolha de ar para dentro da bobina coletora, pois esta segunda bolha entraria na cela de difusão podendo se difundir para a solução receptora. A mistura doadora foi então injetada através da porta 7 de RV, a uma vazão de $50 \mu \mathrm{L} \mathrm{s}^{-1}$, em direção a RC1 e à cela de difusão. Nesta etapa foram dispensados $1560 \mu \mathrm{L}$, evitando-se que a bolha de ar entrasse na cela de difusão.

BOBINA COLETORA

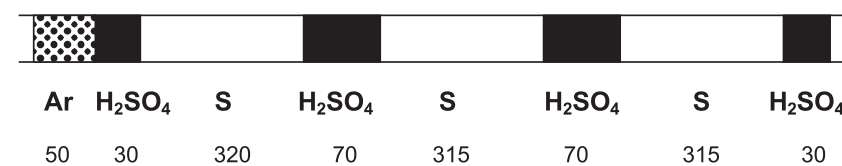

Figura 3. Perfil de solução de ácido sulfúrico $\left(\mathrm{H}_{2} \mathrm{SO}_{4}\right)$ e solução de trabalho de sulfeto (S) aspirada para a bobina coletora para a formação de $H_{2} S$ a ser difundido. Os números indicam o volume de cada zona em $\mu L$. Os tamanhos das zonas não estão em escala

Na seqüência foram aspirados para $\mathrm{HC}$, a uma vazão de $50 \mu \mathrm{L} \mathrm{s}^{-1}$, $70 \mu \mathrm{L}$ da solução receptora através da porta 8 de RV. Estes $70 \mu \mathrm{L}$ são o volume estimado do tubo de Teflon que conecta a porta 8 da válvula seletora à cela de difusão. Este volume foi descartado através da porta $2(\mathrm{~W})$ juntamente com a dispensa de $400 \mu \mathrm{L}$ da solução transportadora.

Finalmente, o pistão começou a aspirar seqüencialmente $200 \mu \mathrm{L}$ de DMPD (R1) pela porta $6,150 \mu \mathrm{L}$ da solução receptora pela porta 8 e $200 \mu \mathrm{L}$ de $\mathrm{FeCl}_{3}(\mathrm{R} 2)$ pela porta 4 . A solução receptora foi aspirada com uma vazão de $50 \mu \mathrm{L} \mathrm{s}^{-1}$ e tanto R1 como R2 foram aspirados com uma vazão de $100 \mu \mathrm{L} \mathrm{s}^{-1}$. Por fim, a válvula seletora mudou para a porta 1 e a seringa foi esvaziada, através da bobina de reação RC2, em direção ao detector, com uma vazão também de $100 \mu \mathrm{L} \mathrm{s}^{-1}$. Tais parâmetros foram otimizados em estudo anterior ${ }^{15}$, visando a determinação de sulfeto pelo método SIA sem difusão gasosa.

\section{RESULTADOS E DISCUSSÃO}

\section{Otimização dos parâmetros experimentais}

Os parâmetros experimentais que influenciam a difusão gasosa são, entre outros, a geometria da cela, a vazão, o tipo de membrana utilizada, a razão entre as vazões (e entre as pressões) do fluxo doador e receptor e o comprimento da cela ${ }^{1,16-19}$. A fim de obter-se uma maximização do sinal analítico estes parâmetros devem, sempre que possível, ser otimizados.

Na configuração proposta neste trabalho, a solução receptora mantém-se parada na cela de difusão enquanto a solução doadora flui pela parte inferior da cela de difusão. O sistema proposto foi estudado com soluções padrões de sulfeto, procurando-se verificar a influência da concentração da solução receptora de $\mathrm{NaOH}$, da vazão da solução doadora e do volume de solução receptora injetada na intensidade do sinal analítico.

Um parâmetro adicional de otimização que pode ser estudado é o volume de amostra utilizado para gerar a espécie $\mathrm{H}_{2} \mathrm{~S}$. No entanto, este volume é limitado pela capacidade da bobina coletora. Neste trabalho, utilizaram-se $950 \mu \mathrm{L}$ de volume de amostra e $200 \mu \mathrm{L}$ de $\mathrm{H}_{2} \mathrm{SO}_{4}$ fracionados de acordo com o perfil mostrado na Figura 3, sendo utilizada a bolha de ar para evitar a dispersão da zona reacional com a solução transportadora. Esta bolha também permitiu o acompanhamento visual da posição da zona reacional no interior da bobina coletora, podendo-se assim evitar a entrada da zona reacional no interior da seringa.

\section{Concentração da solução receptora de $\mathrm{NaOH}$}

A concentração desta solução foi estudada na faixa de 5 a $200 \mathrm{x}$ $10^{-3} \mathrm{~mol} \mathrm{~L}^{-1}$. Inicialmente esperava-se que uma maior concentração da solução receptora favorecesse a difusão do $\mathrm{H}_{2} \mathrm{~S}$. No entanto, os dados experimentais revelam que a concentração da solução receptora de $\mathrm{NaOH}$ não exerce nenhuma influência no sinal analítico, pois as absorbâncias observadas para as diferentes concentrações da solução receptora não apresentaram uma tendência bem definida. Observou-se uma variação aleatória da absorbância num intervalo de 0,22 a 0,26 para uma solução de sulfeto $5 \mathrm{mg} \mathrm{L}^{-1}$. Em função deste resultado, adotou-se a solução de $\mathrm{NaOH} 25 \times 10^{-3} \mathrm{~mol} \mathrm{~L}^{-1}$ como solução receptora, uma vez que esta concentração já vinha sendo utilizada em estudos anteriores ${ }^{15,20}$.

\section{Vazão da solução doadora}

Em relação à vazão da solução doadora, o esperado era que quanto menor a vazão, mais o $\mathrm{H}_{2} \mathrm{~S}$ iria difundir e, portanto, maior o sinal analítico obtido, como relatado por Schulze et al. ${ }^{18}$. Os dados experimentais obtidos confirmaram esta predição, conforme mostra a Figura 4, na qual se apresentam os resultados obtidos para uma variação da vazão de 10 a $100 \mu \mathrm{L} \mathrm{s}^{-1}$. Pode-se observar que este parâmetro afeta substancialmente o sinal analítico. Para uma solução de sulfeto $5,0 \mathrm{mg} \mathrm{L}{ }^{-1}$, utilizando-se uma vazão de 75 ou $100 \mu \mathrm{L} \mathrm{s}^{-1}$, o sinal analítico foi da ordem de 0,2 unidades de absorbância, ao passo que para uma vazão de $10 \mu \mathrm{L} \mathrm{s}^{-1}$, a absorbância medida no máximo do pico foi de 0,36 unidades, representando um ganho de cerca de $80 \%$ no sinal. Portanto, a vazão da solução doadora é de fundamental importância para adequar a sensibilidade do método à concentração da amostra. Assim, amostras mais diluídas requereriam menores va-

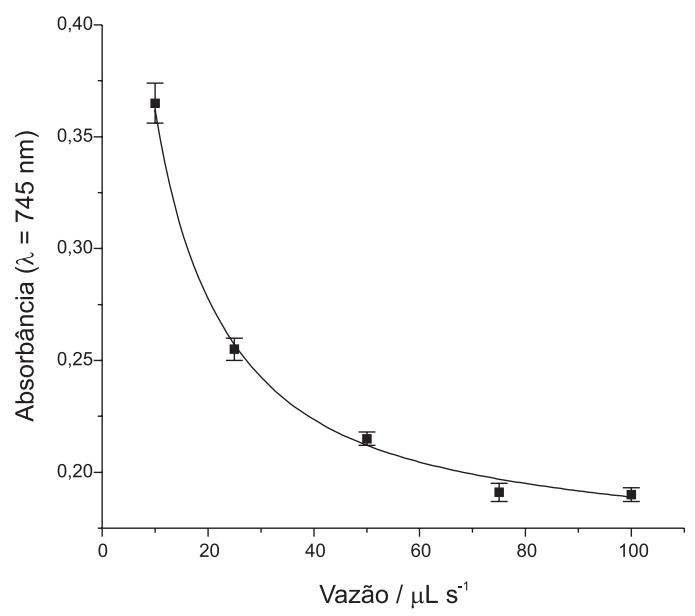

Figura 4. Efeito da vazão da solução doadora de sulfeto $5 \mathrm{mg} \mathrm{L}^{-1}$. O volume aspirado da solução receptora $\left(\mathrm{NaOH} 25 \times 10^{-3} \mathrm{~mol} \mathrm{~L}^{-1}\right)$ foi de $150 \mu \mathrm{L}$ 
zões, da ordem de $10 \mu \mathrm{L} \mathrm{s}^{-1}$, ao custo de uma queda na freqüência de amostragem que, para esta vazão, seria da ordem de 12 amostras $\mathrm{h}^{-1}$. Por outro lado, uma vazão de $50 \mu \mathrm{L} \mathrm{s}{ }^{-1}$ resulta em uma absorbância na altura máxima de pico de 0,22 e em uma freqüência de amostragem de $20 \mathrm{~h}^{-1}$. Este fato mostra que o preparo prévio do sistema para realizar a difusão tem uma importante contribuição na limitação do tempo de análise, pois uma diminuição de cinco vezes na vazão (50 para $10 \mu \mathrm{L} \mathrm{s}^{-1}$ ) diminuiu a freqüência de amostragem por um fator de 0,6 , ao passo que se apenas a etapa de difusão limitasse a velocidade analítica, o fator de queda seria 0,2 .

\section{Influência do volume amostrado de solução receptora}

Por fim, otimizou-se o volume aspirado de solução receptora da cela de difusão durante a etapa de determinação propriamente dita. Estudos anteriores ${ }^{15}$ utilizando a técnica SIA convencional (sem difusão gasosa) revelaram um volume otimizado de $150 \mu \mathrm{L}$ de solução de sulfeto para $200 \mu \mathrm{L}$ de DMPD e Fe(III). Volumes maiores que $150 \mu \mathrm{L}$ não levavam a um aumento de sinal devido à baixa interpenetração entre as zonas de amostra e reagente. No caso da cela de difusão gasosa, com a concentração do DMPD utilizado sendo de $3,63 \times 10^{-3} \mathrm{~mol} \mathrm{~L}^{-1}$, elevando-se o volume aspirado para valores iguais ou superiores a $175 \mu \mathrm{L}$ observa-se uma acentuada queda de sinal (Figura 5). Essa queda pode ser atribuída à baixa interpenetração das zonas de amostra e reagentes e à existência de um gradiente de concentração dentro da solução receptora. Neste último caso, se estaria amostrando, além da solução rica em sulfeto difundido, elementos de solução receptora com baixa concentração do analito.

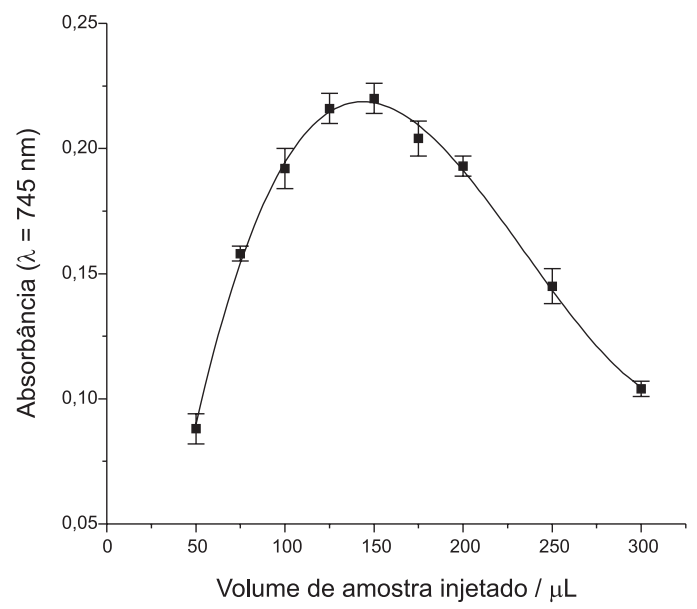

Figura 5. Efeito do volume de solução receptora ( $\mathrm{NaOH} 25 \times 10^{-3} \mathrm{~mol} \mathrm{~L}^{-1}$ ) aspirada para análise. Solução doadora de sulfeto $5 \mathrm{mg} \mathrm{L}^{-1}$, vazão $50 \mu \mathrm{L} \mathrm{s}^{-1}$

Um recurso para aumentar o sinal analítico seria amostrar toda a solução receptora utilizando-se o conceito de amostragem binária ${ }^{14}$, que promoveria o aumento da interpenetração entre as zonas. Outra possibilidade seria utilizar o conceito de análise em fluxo contínuo monossegementado ${ }^{20,21}$ para amostrar a solução receptora. Além de resolver o problema da interpenetração, ainda evitaria a dispersão da zona reacional com a solução transportadora.

\section{Curva analítica}

Adotando-se as seguintes condições experimentais: $950 \mu \mathrm{L}$ de volume de amostra para gerar $\mathrm{H}_{2} \mathrm{~S}$, solução receptora de $\mathrm{NaOH} 25 \mathrm{x}$ $10^{-3} \mathrm{~mol} \mathrm{~L}^{-1}$ vazão da solução doadora de $\mathrm{H}_{2} \mathrm{~S}$ de $50 \mu \mathrm{L} \mathrm{s}^{-1}$ e $150 \mu \mathrm{L}$ de solução receptora aspirada para análise, estudaram-se soluções de sulfeto com concentrações entre 0,10 e $4,0 \mathrm{mg} \mathrm{L}^{-1}$.
Os sinais analíticos transientes sobrepostos são mostrados na Figura 6. As absorbâncias medidas na altura máxima de pico, quando colocadas em função da concentração de sulfeto (gráfico inserido na Figura 6), resultaram na seguinte equação linear: $\mathrm{Abs}=(0,0705 \pm$ $0,0008)\left[S^{2-}\right]-(0,001 \pm 0,001)$, com coeficiente de correlação (R) 0,9995 . O limite de detecção calculado pelo método de propagação de $\operatorname{erros}^{22}$ foi de $60 \mu \mathrm{g} \mathrm{L} \mathrm{L}^{-1}$, com uma frequiência de amostragem de 20 determinações por hora. O limite de detecção foi da mesma ordem de magnitude daquele observado por SIA convencional ${ }^{15}$, ou por SIA associado com análise por fluxo monossegmentado ${ }^{20}$, embora com freqüência analítica inferior.

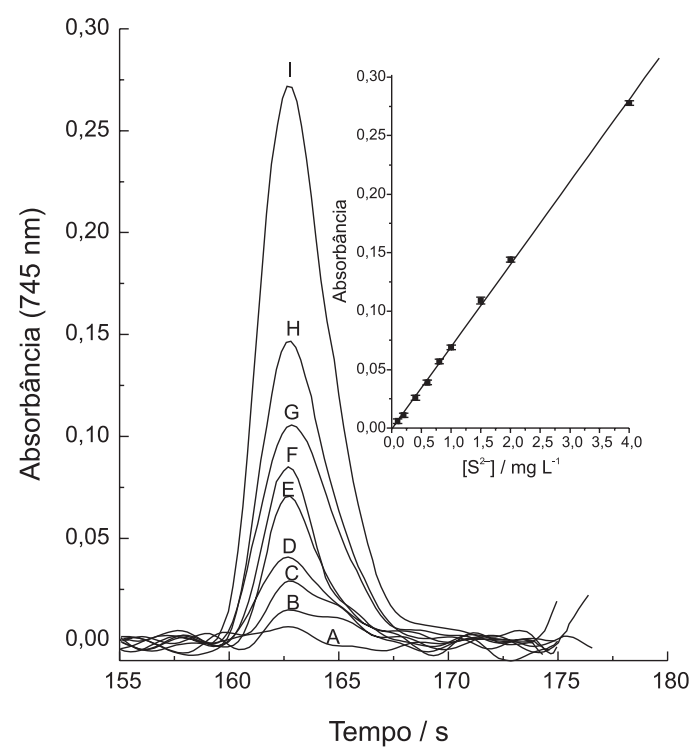

Figura 6. Sinais analíticos para concentrações de $S^{2-}$ de (A) 0,10; (B) 0,20; (C) 0,40; (D) 0,60; (E) 0,80; (F) 1,0; (G) 1,5; (H) 2,0 e (I) 4,0 mg L L $^{-1}$ obtidas com o sistema descrito na Figura 1. Concentração de NaOH receptor $25 x$ $10^{-3} \mathrm{~mol} \mathrm{~L}^{-1}$, vazão da solução doadora $50 \mu \mathrm{L} \mathrm{s} \mathrm{s}^{-1}$ e volume aspirado de solução receptora de $150 \mu \mathrm{L}$. A figura inserida corresponde à curva analítica

A faixa de resposta linear do método proposto foi maior que em outros métodos baseados em SIA ou FIA já descritos na literatura $^{15,20,23}$, podendo estender-se até $4,0 \mathrm{mg} \mathrm{L}^{-1} \mathrm{em} \mathrm{S}^{2-}$, porém com a grande vantagem de realizar a mudança de matriz em linha. Nas condições utilizadas não se obteve um efeito de pré-concentração ou ganho de sensibilidade em relação ao SIA convencional. Um aumento de sensibilidade da metodologia proposta envolveria a diminuição da vazão da solução doadora na etapa de difusão gasosa, bem como um aumento do volume de amostra utilizado para gerar $\mathrm{H}_{2} \mathrm{~S}$. Neste último caso, sem alterar a configuração mecânica do sistema, o volume poderia ser dobrado ou triplicado, repetindo-se a sub-rotina de geração de $\mathrm{H}_{2} \mathrm{~S}$ duas ou três vezes, mantendo-se a solução receptora parada na cela de difusão.

Nas atuais condições, o método seria aplicável na determinação de sulfeto em amostras complexas como águas residuárias, esgotos e sedimentos, bem como águas minerais sulfurosas. Tais amostras podem ser coloridas ou apresentar sólidos em suspensão, ou ainda agentes redutores que poderiam interferir na determinação. Nestas situações a aplicação da técnica aqui proposta seria útil por realizar a chamada troca de matriz, em que o analito é separado dos possíveis interferentes. Pretende-se em trabalhos futuros dar prosseguimento à otimização da sensibilidade do método no sentido de obter-se, além da mudança de matriz, um efeito de pré-concentração no volume de solução receptora, visando a determinação de sulfeto em águas naturais. 


\section{CONCLUSÕES}

É possível realizar a associação da análise por injeção seqüencial a celas de difusão gasosa sem a necessidade de bombas ou válvulas auxiliares. Esta associação permite a eliminação de interferentes por mudança de matriz, o que pode ser desejável no caso de amostras complexas, nas quais uma adição de padrão não seria eficiente para realizar a determinação. O procedimento seria agilizado com a utilização de uma válvula seletora com maior número de portas, economizando tempo de preparo do sistema antes de realizar a difusão gasosa e a determinação propriamente ditas. Nas condições aqui descritas foi possível realizar a troca de matriz, mas não o ganho de sensibilidade (pré-concentração) em relação ao método de SIA convencional.

\section{AGRADECIMENTOS}

Os autores agradecem à FAPESP, CNPq e CAPES pelos auxílios financeiros e bolsas de estudo.

\section{REFERENCIAS}

1. Fang, Z.; Flow Injection Separation and Preconcentration, VHC, Weinheim: Germany, 1993.

2. Silva, F. V.; Nogueira, A. R. A.; Souza, G. B.; Cruz, G. M.; Anal.Sci. 2000 , 16,361 .
3. Silva, F. V.; Nogueira, A. R. A.; Souza, G. B.; Reis, B. F.; Araújo, A. N.; Montenegro, M. C. M. B. S.; Lima, J. L. F. C.; Talanta 2000, 53, 331.

4. Segundo, M. A.; Rangel, A. O. S. S.; Anal. Chim. Acta 2001, 427, 279.

5. Echols, R. T.; James, R. R.; Aldstadt, J. H.; Analyst 1997, 122, 315.

6. Liu, S.; Dasgupta, P. K.; Anal. Chim. Acta 1995, 308, 281.

7. Luo, Y.; Al-Othman, R.; Christian, G. D.; Ruzicka, J.; Talanta 1995, 42, 1545.

8. Lukkari, I.; Ruzicka, J.; Christian, G. D.; Fresenius' J. Anal. Chem. 1993, $346,813$.

9. Oms, M. T.; Cerdà, A.; Cladera, A.; Cerdà, V.; Forteza, R.; Anal.Chim. Acta 1996, 318, 251.

10. Oms, M. T.; Cerdà, A.; Cerdà, V.; Electroanalysis 1996, 8, 387.

11. Ruzicka, J.; Marshall, G. D.; Anal. Chim. Acta 1990, 237, 329.

12. Reis, B. F.; Arruda, M. A. Z.; Zagatto, E. A. G.; Ferreira, J. R.; Anal. Chim. Acta 1988, 206, 253.

13. Nogueira, A. R. A.; Brienza, S. M. B.; Zagatto, E. A. G.; Lima, J. L. F. C.; Araújo, A. N.; Anal. Chim. Acta 1993, 276, 121.

14. Reis, B. F.; Giné, M. F.; Zagatto, E. A. G.; Lima, J. L. F. C.; Lapa, R.; Anal. Chim. Acta 1994, 293, 129.

15. Silva, M. S. P.; da Silva, I. S.; Abate, G.; Masini, J. C.; Talanta 2001, 53, 843.

16. Canham, J. S.; Gordon, G.; Pacey, G. E.; Anal. Chim. Acta 1988, 209, 157.

17. van der Linden, W. E.; Anal. Chim. Acta 1983, 151, 359.

18. Schulze, G.; Liu, C. Y.; Brodowsky, M.; Elsholz, O.; Frenzel, W.; Möller, J.; Anal. Chim. Acta 1988, 214, 121.

19. Karlberg, B.; Pacey, G. E.; Flow Injection Analysis - A practical guide, Elsevier Science Publishers B.V.: Amsterdam, 1989.

20. Silva, M. S. P.; Galhardo, C. X.; Masini, J. C.; Talanta 2003, 60, 45.

21. Pasquini, C.; Oliveira, W. A.; Anal.Chem. 1985, 57, 2575.

22. Long, G. L.; Winefordner, J. D.; Anal. Chem. 1983, 55, 712A.

23. Martelli, P. B.; Rocha, F. R. P.; Gorga, R. C. P.; Reis, B. F.; J. Braz. Chem. Soc. 2002, 13, 642 . 